\title{
Retinal "Caratopathy": Diamond Dust Residuals after Surgeries
}

\author{
Alexander Hüther ${ }^{a, b}$ Timothy T. You ${ }^{a} \quad$ Sanford Chen ${ }^{a} \quad$ Rajiv R. Rathod ${ }^{a}$ \\ Esther L. Kim ${ }^{\mathrm{a}}$ John M. Maggiano ${ }^{\mathrm{a}}$ \\ a Orange County Retina Group, Santa Ana, CA, USA; 'b Tufts University School of Medicine, \\ Boston, MA, USA
}

\section{Keywords}

Crystalline retinopathy $\cdot$ Diamond dust retinopathy $\cdot$ Diamond-dusted scraper $\cdot$ Epiretinal membrane $\cdot$ Macular hole

\begin{abstract}
Diamond dust particles were identified within patients' eyes both during vitrectomy procedures using diamond-dusted membrane scrapers and in postoperative clinical examinations. The particles had no impact on the patients' vision and caused no apparent sequelae. Scanning electron microscopy analysis showed the average particle size to be $23.4 \mu \mathrm{m}$ and an unequal surface area for particle adhesion onto the soft tip. It was determined that diamond dust particles can dislodge from the silicone tip of the Tano diamond-dusted membrane scrapers during the insertion into valve trocars throughout vitrectomy operations and deposit on the retinal surface or within macular holes. Ophthalmologists should be aware of residual diamond particles during procedures and consider diamond dust retinopathy in the differential diagnosis of crystalline retinopathies. Understanding the appearance of residual particles on the retina allows for future studies revealing the long-term impact on patient's visual performance.
\end{abstract}




\section{Case Reports in Ophthalmology}

\section{Introduction}

Surgical techniques and tools have evolved in the treatment of patients with macular holes and epiretinal membranes. One surgical tool which is commonly utilized is a diamonddusted microspatula instrument to initiate a flap allowing for the removal of the internal limiting membrane or the epiretinal tissue [1]. Tiny diamond particles are glued using silicone adhesives to the flexible silicone at the distal end of a plastic handle. During vitrectomy operations, the crystalline-dust tip is gently applied to the epiretinal surface. Rarely, these diamond particles can become dislodged intraoperatively and remain in the eye as intraocular foreign bodies. Gupta and Goldsmith [2] described the presence of diamond particles within the eye after surgical procedures using diamond-dust scraper instruments. The carbon particles were observed as little white particulates, which became visible on the retinal surface after the vitrectomy surgeries. In another reported case, the diamond particles deposited in the subfoveal location after a surgical procedure was performed to treat a macular hole [3]. In these cases, the appearance of the carbon dust within the eye did not impair vision and did not result in any acute retinal toxicity. A different case report presented the presence of diamond dust particles in the eye using spectral-domain optical coherence tomography (SD-OCT) [4]. In the white-on-black OCT images, the particles appeared as bright, highly reflective white spots, which appeared to be deposited in the intraretinal region of the macula after successful macular hole closure. Reported cases of diamond dust on the retina are extremely uncommon, considering the total number of surgeries employing a diamond-dusted scraper. We present a case series of 3 patients who demonstrated diamond particles throughout the operative procedure as well as upon postoperative examination, associated with vitrectomy surgeries, and propose a mechanism for how diamond dust retinopathy can develop.

\section{Case Presentation}

\section{Case 1}

An 80-year-old male patient was seen for vision loss and was diagnosed with cystoid macular edema and epiretinal membrane in the left eye with 20/250 preoperative visual acuity. The subject had undergone previous cataract surgery and presented with pseudophakia OU. After failing to improve with medical therapy, the patient underwent a vitrectomy surgery with membrane peeling using a Tano diamond-dusted membrane scraper (Synergetics Inc., O'Fallon, MO, USA) as well as 23-gauge valve trocars (Alcon, Fort Worth, TX, USA). The dislodging of the diamond crystals from the silicone spatula tip was not evident during the vitrectomy operation. Postoperatively, the visual acuity was $20 / 200$ in the left eye. No anterior segment findings were evident, but the patient had five uniform white particles in the paracentral epiretinal region during clinical examination and fundus photography (Fig. 1a, b). The particles were not evident in SD-OCT imagery (online suppl. Fig. S1; for all online suppl. material, see www.karger.com/doi/10.1159/000506623).

\section{Case 2}

A 73-year-old diabetic white male complained about loss of vision in the left eye. His visual acuity was $20 / 20$ for the right eye and count fingers for the left eye. The patient presented with progressively worsening nuclear sclerosis $3+$ OU. OCT imaging confirmed a chronic macular hole in the patient's left eye. Macular hole repair surgery was performed using 25-gauge valve trocars (Alcon) as well as a Tano diamond-dusted membrane scraper (Synergetics Inc.) 
for membrane peeling. The macular hole persisted despite surgical treatment. Slit-lamp examination after the procedure showed the appearance of a solitary white diamond particle within the eye. The particle within the unclosed macular hole was identified to be resting on the retinal pigment epithelium through SD-OCT imaging (Fig. 2). Postoperative vison was determined to be count fingers at $4 \mathrm{ft}$ for the left eye.

\section{Case 3}

A 41-year-old white female patient was seen for decreased vision in her right eye related to vitreomacular traction syndrome. Examination presented no anterior segment findings besides incipient senile cataracts OU. The visual acuity was 20/260 in her right eye and 20/25 in her left eye. A vitrectomy procedure using the Tano diamond-dusted membrane scraper (Synergetics Inc.) and 23-gauge valve trocars (Alcon) was performed on the patient's right eye. Two diamond crystals dislodged from the silicone tip during the surgery onto the retina (online suppl. Fig. S2). Multiple attempts at aspirating the particles were unsuccessful. Postoperatively, here vison was 20/125 in her right eye. The diamond particles could not be identified by postoperative clinical examination (online suppl. Fig. S3, S4).

\section{Conclusion}

Each of the patients in this case series underwent a vitrectomy operation for the treatment of a macular hole or an epiretinal membrane. The surgical technique employed by two surgeons (T.T.Y., S.C.) had in common the use of a diamond-dusted membrane scraper using 23-gauge or 25-gauge trocars with a silicone valve. In 1 patient of our series, the diamond particles were discovered during the scraping process, but could not be removed at the completion of the vitrectomy procedure despite multiple attempts. In the other 2 patients, the diamond particles were discovered postsurgically. After analysis of the diamond-dusted tip and the particles themselves (Fig. 3), we hypothesize that the insertion of the tool into the valve trocar loosens the diamond particles on the flexible sleeve, as the laxity of the sleeve causes a folding of the silicone tip. Moreover, repeated insertion and removal of the Tano scraper further weakens the adhesion of the diamond crystals to the silicone tip. The friction caused by the mechanical action allows for the dislodging of the crystals from the silicone.

Scanning electron microscopy (SEM) was performed to determine the average particle size of the diamonds, which was found to be $24.3 \mu \mathrm{m}$ and revealed multilayer, particulate attachment on the silicone tip. Individual particles do not possess the same surface area for adhesion to the tip's surface, which may account for nonuniform adhesion to the tip. Fortunately, the diamond dust particles previously reported in the literature did not create any functional impairment nor were proven to have any clinical impact $[2,3]$. The patients in this case series also did not show any sequelae of the diamond dust. Because the particles are not fixed to the retinal surface and can move within the globe, as noted throughout the surgeries, some of the particles were not evident upon postsurgical clinical examinations. Additionally, it is possible that the particles are not evident during funduscopic examinations, as they could require a certain angle of incident light to refract and allow them to become visible.

Synergetic Inc. has since released a modified tool that may eliminate this surgical complication. This enhanced tool allows for the tip to be protected during insertion by moving a metallic cylinder over the tip, a process controlled by a small black knob on the tool. Other retinal surgical manufacturers such as Alcon have introduced a FINESSE ${ }^{\mathrm{TM}}$ Flex Loop membrane scraper, which uses a single retractable loop without any adhered particles. 
Ophthalmologists should be aware of diamond dust when using the Tano diamonddusted membrane scraper and consider diamond dust retinopathy in the differential diagnosis of crystalline retinopathies. Long-term studies regarding the impact of the diamond particulates on visual acuity have not been performed and could be of interest for future studies.

\section{Acknowledgements}

We would like to thank the Chemistry Department of Trinity University, San Antonio, for allowing us to use their SEM equipment and helping in the acquisition of SEM images.

\section{Statement of Ethics}

Consent to publish the case report was not obtained, since patients could not be contacted. This report has been deemed by the authors to be sufficiently anonymized and does not contain any personal information that could lead to the identification of the patients in accordance with the Declaration of Helsinki.

\section{Disclosure Statement}

There is no proprietary interest in this work for any of the authors.

\section{Funding Sources}

The authors received no funding or grant support.

\section{Author Contributions}

SEM images were taken by Alexander Hüther. Interpretation and analysis of the cases were done by Alexander Hüther, Timothy T. You, Sanford Chen, Rajiv R. Rathod as well as John M. Maggiano. Acquisition of the images was performed by Alexander Hüther and Timothy T. You. The surgical procedures were performed by Timothy T. You and Sanford Chen. The case report formation and concept creation were done by Timothy T. You and Alexander Hüther. All authors took part in drafting and revising the final version of the case series.

\section{References}

1 Tolentino FA, Wu G. Diamond-dusted microspatula tips for vitreoretinal surgery. Arch Ophthalmol. 1987 Dec;105(12):1732-3.

2 Gupta D, Goldsmith C. Iatrogenic retinal diamond deposits: an unusual complication of using the diamonddusted membrane scraper. Eye (Lond). 2009 Aug;23(8):1751-2.

3 Tan LL, Ng D, Kierans M, Kernohan N, Cormack TG. Iatrogenic subfoveal diamond particle after macular hole repair surgery. Retin Cases Brief Rep. 2013;7(4):328-30.

4 Bae SW, Choi DK, Chae JB. Spectral domain optical coherence tomography findings of an iatrogenic retinal diamond deposit. Eye (Lond). 2011 Nov;25(11):1518-9. 


\section{Case Reports in Ophthalmology}

\begin{tabular}{l|l}
\hline Case Rep Ophthalmol 2020;11:137-142 \\
\hline DOI: 10.1159/000506623 & $\begin{array}{l}\text { @ 2020 The Author(s). Published by S. Karger AG, Basel } \\
\text { www.karger.com/cop }\end{array}$ \\
\hline
\end{tabular}

Hüther et al.: Retinal "Caratopathy": Diamond Dust Residuals after Surgeries

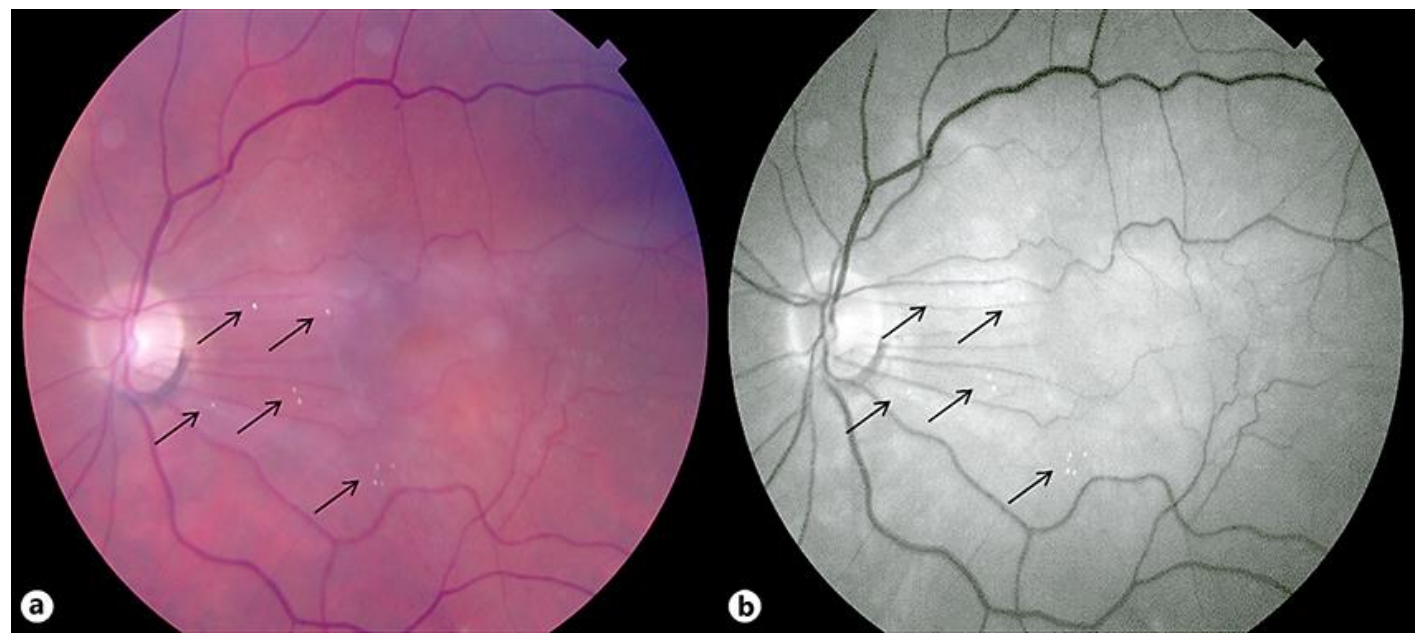

Fig. 1. a Fundus image of the left eye. White diamond deposits are marked. b Red-free photograph. Carbon particles are highly visible and distributed in the nasal macula.

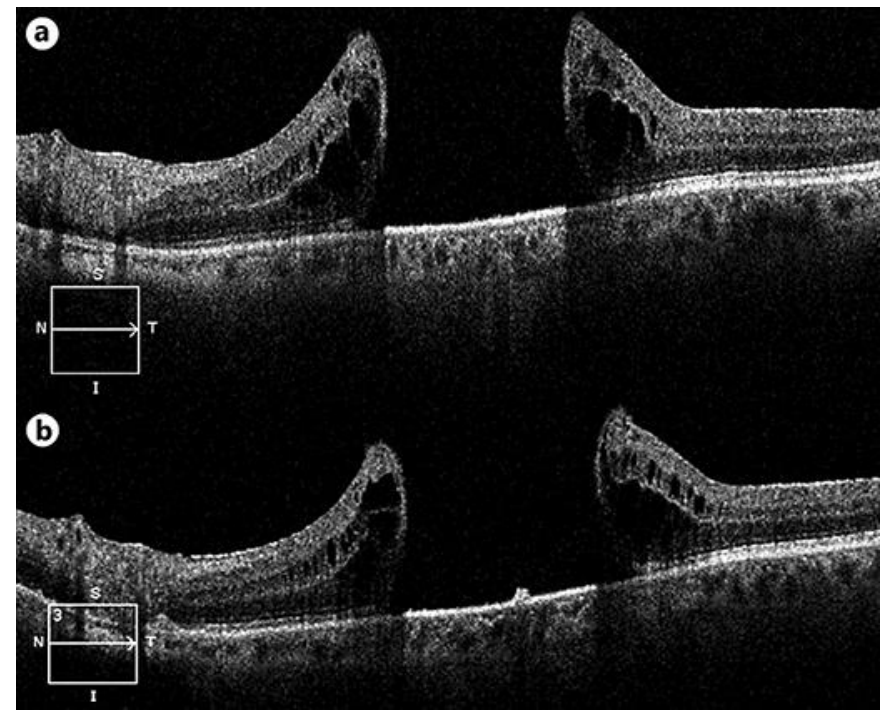

Fig. 2. SD-OCT images of the macular region. a Macular hole before surgical treatment was performed. b Macular hole which remained open after surgical treatment with a refractive particle lying on the retinal pigment epithelium layer. 


\section{Case Reports in Ophthalmology}

\begin{tabular}{l|l}
\hline Case Rep Ophthalmol 2020;11:137-142 \\
\hline DOI: 10.1159/000506623 & $\begin{array}{l}\text { c 2020 The Author(s). Published by S. Karger AG, Basel } \\
\text { www.karger.com/cop }\end{array}$ \\
\hline
\end{tabular}

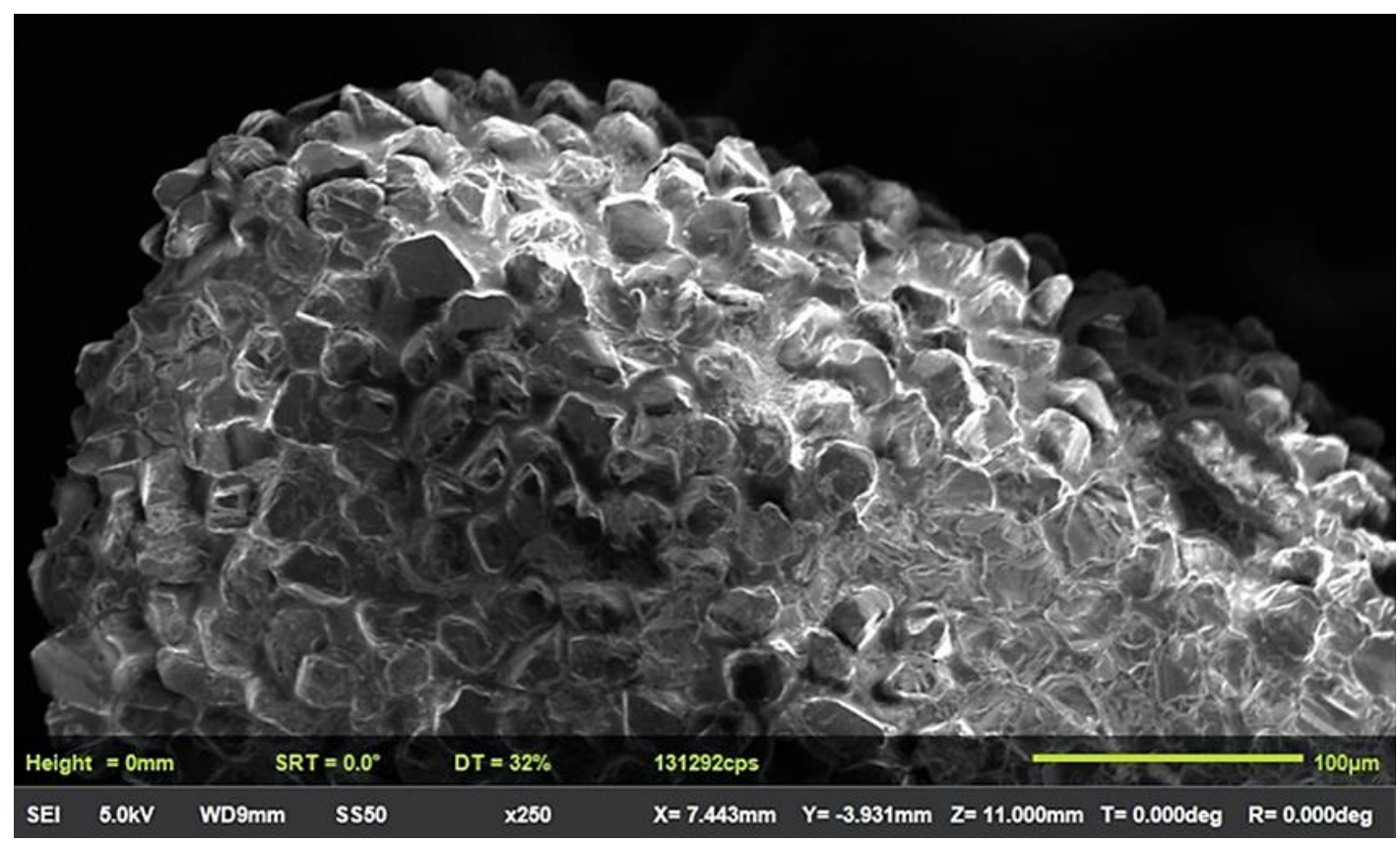

Fig. 3. Scanning electron microscope image of Tano diamond-dusted membrane scraper (Synergetics Inc.) at $\times 250$ magnification. Notice how particles are partially stacked upon each other, decreasing the area of adhesion possible to the tip. 